\title{
БИОТИЗАЦИЯ ОБРАЗА ЖИЗНИ ОБЫВАТЕЛЯ В ИДЕОЛОГИЧЕСКОЙ ТРАДИЦИИ АМЕРИКАНСКОГО ФИЛЬМА УЖАСОВ
}

\author{
Маленко Сергей Анатольевич, \\ olenia@mail.ru \\ Некита Андрей Григорьевич, \\ beresten@mail.ru
}

Новгородский государственный университет имени Ярослава Мудрого, Россия, 173003, Великий Новгород, ул. Большая Санкт-Петербургская, 41.

Маленко Сергей Анатольевич, доктор философских наук, профессор, заведующий кафедрой философии, культурологии и социологии Новгородского государственного университета имени Ярослава Мудрого.

Некита Андрей Григорьевич, доктор философских наук, профессор кафедры философии, культурологии и социологии Новгородского государственного университета имени Ярослава Мудрого.

\begin{abstract}
Актуальность. Переосмысление классических политических доминант актуализирует смыслы взаимодействия государства, общества и индивида. Отказ от прямого физического принуждения побуждает к поиску идеологических механизмов социального контроля. Голливуд становится медийным рупором биотической трансформации политики, а фильм ужасов превращается в наиболее эффективную модель визуализации этих технологий. Цель работы - проанализировать методологические стратегии биотизации обывательской повседневности в пространстве современной массовой культуры посредством идеологической экспансии традиции американских фильмов ужасов. Методы: комплекс компаративистских, семиотических и психоаналитических методов, анализирующих художественный опыт кинематографа и его мифологию. Результаты. Голливудские фильмы ужасов выступают апробированным средством сублимации, деформации и потребительского замещения ментального ядра любых конкурирующих социокультурных традиций. Американская визуальная хоррор-культура эффективно вытесняет потенциал агрессии внутри страны, превращаясь в прибыльную пропагандистскую технологию формирования и продвижения патомифа. Он воспроизводит преимущественно физиологические мотивы коммуникации индивида с окружающим миром, пропагандирует идейную доминанту биологически сильной особи как фундамент социокультурной коммуникации постчеловеческого типа. Американский фильм ужасов обнуляет экзистенциальный опыт человечества и находится в авангарде ревизии традиций не только европейской, но и мировой культуры. Выводы. Голливудская модель биовласти разрушает культурные традиции и исторический опыт, конструирует и продвигает антропологическую и социокультурную сингулярность человеческой особи, понимаемую как ее единичность в противостоянии отчужденному социуму, а периодически накапливающаяся «интоксикация» голливудским ужасом компенсируется иллюзией американской геополитической гегемонии.
\end{abstract}

Ключевые слова: Американские фильмы ужасов, идеология страха, биовласть, сублимация, вытеснение, обыватель, массовая культура.

История США, в отличие от большинства государств Европы, скоротечна, как сеанс кинофильма, в качестве главных сюжетных линий которого выступают несколько достаточно жутких и поистине неприглядных эпизодов. Во-первых, речь идёт о гено- 
циде, т. е. целенаправленном физическом уничтожении фактически сбежавшего от европейского правосудия маргинальными элементами коренного населения Северной Америки (вплоть до «резервирования» их в отдельных весьма не пригодных для жизни территориях). Во-вторых, имеется в виду полное уничтожение бизона как главного млекопитающего материка. В-третьих, подразумевается кровавая бойня Гражданской войны между Севером и Югом 1861-1865 гг., навсегда закрепившая парадоксальные смыслы рабовладельческого капитализма и ментальности в самой основе политической и социальной системы США. В-четвёртых, необходимо помнить о созданной в 1865 г. и существующей и по сей день ультраправой расистско-националистической организации «Ку-клукс-клан» (англ. «Ku Klux Klan») и ужасных преступлениях ее членов, одетых в белый балахоны и высокие клобуки. Ее адепты - головорезы с факелами в руках «творчески» перенесли опыт жестоких расправ над темнокожим населением США с полей Гражданской войны на улицы американских городов и поселков. В-пятых, нельзя забывать о практике бессознательной компенсации тяжелого эмоционального состояния американского общества в период между Первой мировой войной и Великой депрессией 1929-1939 гг. После таких «приквелов» история «фабрики грез» в XX в., наскоро «сформировав олигополистический Трест» [1], просто не могла не пополниться главой о существовании в ней особого «цеха», поставившего себе цель визуализировать, а заодно и идеологизировать весь тот ужас, который накопился в предельно рационализированной истории западной цивилизации. Алексей Юсев так пытается охарактеризовать специфику Голливуда: «Американский кинематограф всегда был рефлексией идей, фантазий и страхов американцев, а не только того, что называется мейнстрим. Современный американский кинематограф демонстрирует нам странный сплав мифов прошлого [...] и страхов перед будущим [...] и некомфортности настоящего [...]. Вот, собственно, это и есть образ Америки, в который погружается «средний американец», покупая билет в кино» [2, с. 6-7].

Однако в условиях, когда общество массового потребления уже активно наступало на горло монополистическому капитализму, подобные процессы оказались не чем иным, как банальной девальвацией и вытеснением на задворки самой «передовой» культуры мира этих кровавых событий реальной американской истории. Более того, именно голливудская кинопродукция ужаса была одним из ведущих способов социокультурной и в первую очередь идеологической сублимации негативной энергии первого в истории человечества мирового экономического кризиса. Поэтому победоносное шествие этого жанра по планетарному пространству массовой культуры во многом до сих пор подпитывается именно трагическими страницами американской и мировой истории. А две самые разрушительные и кровавые в истории человечества мировые бойни, из которых США всякий раз выходили только изрядно обогатившимися победителями, лишь окончательно утвердили в североамериканской культуре парадоксальный духовный коктейль, смешанный из атмосферы депрессии, вытесненного чувства вины и гипертрофированного комплекса превосходства-непогрешимости. Ж. Бодрийяр уточняет в связи с этой ситуацией собственное понимание специфики Америки: «Истерия раздутости является одним из самых причудливых признаков американской культуры, той призрачной среды, где каким-то образом у каждой клетки [...] остается, как при раке, возможность делиться, множиться до бесконечности, занимать практически все пространство только собой, монополизировать всю информацию только для себя [...]» [3, с. 37]. Поэтому неудивительно, что подобные патологические состояния необходимо было срочно «лечить» с помощью идеологической эскалации внутренней и внешней агрессии как на уровне каждого отдельного «стопроцентного американца», так и всей страны в целом. 
Факты более чем парадоксальные, но между ними есть несомненная связь, которую Голливуд не только очень точно подметил, но своевременно и «правильно», т. е. идеологически, визуализировал. Пройдя такие испытания, Америка научилась не только эффективно, но и уже с XIX в. крайне прибыльно «вытеснять» потенциал внутренней агрессии вовне, закрепив в системе мировой стратификации свое безоговорочное господство над сервильными территориями, находящимися на любом удалении от своих исконных географических границ. Поэтому совершенно не удивительно, что в России, с ее богатейшим кинематографическим опытом, до сих пор так и не удалось наладить производство достойных фильмов ужасов. По мнению авторов, причины этого феномена кроются в том, что у нас просто нет такой богатой и насыщенной чужой кровью и страхами истории, а в недрах нашей ментальности отсутствуют традиции агрессивного вуайеризма, кроваво-кричащего садомазохизма, безумной некрофилии и хищнической некрофагии, столь характерные для эстетическо-идеологической модели голливудских фильмов ужасов, которые в любую эпоху надежно коррелируются с актуальными «политическими и культурными контекстами» [4, с. 118].

Так, исподволь и практически бессознательно процесс формирования американского «ужасного» кинематографа стал хронологией формирования и институционального утверждения технологии бессознательного вытеснения: реальности - вымыслом, сущего - должным, настоящего - экранным, а повседневного - властным. В то же время «в идеологическом контексте американских фильмов ужасов уже само по себе свободное нахождение людей в одном политическом, социальном, культурном и религиозном пространстве без страха и страданий оказывается вообще невозможным и немыслимым» [5, с. 101]. Да и сам голливудский «ужасный» культурный продукт на сегодняшний день выступает для политико-идеологической машины США уже проверенным и хорошо апробированным средством сублимации (в форме пропагандистского заражения), деформации и потребительского замещения архетипической матрицы и символических кодов любых конкурирующих социокультурных традиций.

Следует напомнить, что исходная бессознательная установка Голливуда, как главного идеолого-пропагандистского рупора «Нового Света», изначально формировалась в жесткой духовно-эстетической конкуренции (довольно быстро редуцированной к банальному вытеснению) с традиционными континентальными ценностями Европы, представлявшими цивилизационно отработанный, а потому и морально, и технологически отживший свое Старый Свет. Поэтому верный ницшеанским этическим принципам «переоценки ценностей» и экранному промоушену идеалов «Сверхчеловека» Голливуд с момента своего основания встал на путь бессознательного отрицания героической традиции «старосветских» мифологий, последовательно формируя свой главный козырь, а в перспективе и ведущий идеологический таран - кинообраз «ужасного» антигероя, готовя «для грядущего сильного вида людей высшей духовности и силы воли, медленно, осторожно, исподволь высвобождая для этой цели в людях множество прежде обузданных и оболганных инстинктов» [6, с. 514]. Он изначально виделся заокеанскому режиссеру - «человеку с киноаппаратом» - в качестве постмодернистского антипода классической героической традиции, замещенной «темами психологического доминирования и подчинения, в которых и злодей, и его жертва переживают кризис субъективности, в котором они больше не кажутся авторами своих собственных действий» [7, с. 163]. Потому-то и экранная история становления голливудского антигероя является визуализированным идеологическим патомифом современной потребительской цивилизации, который перетолковал смыслы классического мифа, ориентированные на воссоздание архетипической целостности Космоса, Человека и Общества, и тем 
самым кардинально изменил содержание и саму направленность социализации обывателей, придав ей аутичный, нарциссический, экстремально-негативный и откровенно апокалиптичный характер.

Подобным образом Голливуд вот уже более чем столетие формирует и навязывает «обществу потребления» новый идеал обывателя, этакого стяжателя «американской мечты»: индивида, рефлекторная социальная активность которого напрямую зависит от степени опасности и близости как собственной, так и особенно чужой смерти. Показательно, что именно голливудский «ужасный» патомиф всегда стремится стать последним уроком в жизни любого адепта «американской мечты», фиксируя, таким образом, вслед за ницшеанской «переоценкой всех ценностей» еще и их сублимирующую идеологическую ревизию.

Само по себе появление «ужасного» жанра в американском кинематографе более чем убедительно доказало его генетическую связь с психоанализом, который «стремился утвердить этот жанр, связав его с конкретными теоретическими положениями $[8$, c. 46] и с массовой культурой, в которой целенаправленно отражаются и воспроизводятся преимущественно физиологические, рефлекторно-схематические отношения человека с окружающим миром. Их образное воплощение в американских фильмах ужасов является чередой устрашающих примеров, иллюстрирующих как государственно-идеологический, так и собственно коммерческий векторы эксплуатации чувственноэмоциональной природы человека. Действительно, во многом благодаря американским фильмам ужасов и сформированной ними биотико-пропагандистской доминанте, можно наблюдать на заре третьего тысячелетия цивилизованной истории человечества весьма парадоксальную картину. Ужас как основной персонаж этого жанра способствует полноценной институализации садомазохизма, который в виде насилия, сексуальных извращений, пыток, казней, каннибализма, некрофилии, копрофилии, метамерофилии (тяга к расчленению тел) и т. д. непосредственно манифестирует доминирующие эстетические и политические тренды, становится «моральным уроком для населения, отвлеченного от традиционных американских ценностей» [9, с. 243] и превращается в самодостаточную идеологическую константу, сублимировав, таким образом, архетипические смыслы традиционной культуры.

Что же поделать, если постмодернистская культура столь изощренными способами трансформировала идеалы прекрасного? Последовательно и жестоко иронизируя над классическими образцами красоты, американские фильмы ужасов эстетизируют массовую культуру как оригинальную, альтернативную, «другую» по отношению к классической культуре» $[10$, с. 682] и вот уже более века выступают в авангарде идеологической ревизии духовно-эстетического потенциала европейской цивилизации. Более того, следует признать, что они как минимум «на равных» довольно успешно и прибыльно конкурируют с постмодернистской традицией экранной интерпретации роскоши и великолепия, широко представленной гламуром. Возникает это во многом потому, что в каждой голливудской ужасной киноистории происходит маленький сеанс победоносного, ритуального заклания этих «мнимых» буржуазных идеалов, показывающего обывателям дорогу к пониманию «подлинной» сущности прекрасного. В то же время оказалось, что в дисциплинарном пространстве современной потребительской культуры именно фильмы ужасов помимо своей развлекательной и досуговой функции выполняют ещё и первостепенное социализирующее значение, наглядно представляя собой «чрезвычайно сложный когнитивный процесс и аффективные события» [11, с. 213].

Иначе говоря, голливудские фильмы ужасов, становясь «провокационным шедевром» $[12$, с. 79], идеологическим рупором правящих элит США, фактически сами, в 
конце концов, превращаются в полноценную и самодостаточную хоррор-идеологию. Становясь очень мощным пропагандистским инструментом «мягкой силы», ужасная кинопродукция надежно, а главное, зрелищно и крайне убедительно обеспечивает медийный и биотехнологический ресурс американского истеблишмента. Как ни странно, но как раз американский фильм ужасов в XX и начале XXI вв. стал по сути «культовым фильмом» [13, с. 15], удачно осуществив серьезнейший, идеологически ориентированный, образно-символический ребрендинг классических и новейших трендов социалдарвинизма, от которого официальная политика и наука публично уже давно дистанцировались. Ведь именно идея биологически сильной особи, претендующей на тотальное господство над всеми остальными человеческими организмами и их сообществами, превращенными в «трофическую лужайку» власти, становится ведущим смыслом любого подобного киноповествования.

Действительно, не гнушаясь никакими средствами, не прибегая ни к каким логическим уловкам для оправдания и внедрения своей биотической стратегии, подобная особь на своем пути физически устраняет любых конкурентов, расчищая жизненное пространство для объективации и социализации «джентльменского набора» своих «основных инстинктов». Ведущая же идеология подобной хоррор-стратегии заключается в том, что антигерою, витализирующему мир мертвых поколений, идей и традиций, всякий раз приходится противостоять потребительскому Танатосу мира «живых». Так, жанр киноужаса на протяжении всей истории своего становления демонстрирует человечеству панораму жестокой и кровавой архетипической битвы пока еще невоскресших «мертвых» с так и неожившими «живыми».

Таким образом, небывалая биотехнологическая привлекательность для власти именно этого «ужасного» голливудского жанра состоит в том, что практически в открытую пропагандируемый им соматический дискурс обывателей сублимирует их и без того невостребованные духовные способности и базовые интеллектуальные навыки в комплекс наиболее элементарных физиологических реакций на любые коммуникативные вызовы социальной среды, рефлекторно воспринимающиеся ими как агрессивные.

Подобная форма социального «партнерства» биовласти (системы иерархического управления, ориентированной на создание механизмов и стратегий, базирующихся на произвольной интерпретации и последующей эксплуатации физиологических нужд человека, которым придается общесоциальное и общекультурное значение) и обывателей на любом новом витке развития цивилизации практически полностью обнуляет исторический опыт, культурную традицию и родовые архетипические смыслы. В этой связи показательно, что по мере развития цивилизации подобный дискурс приобретает все более сублимационный характер, позволяющий биовласти произвольно, как на уровне идеологии, так и в пространстве конкретных управленческих практик, конвертировать физиологические принципы бытия индивида в общесоциальные и наоборот. В таком формате любой человек интерпретируется только лишь как обыватель, со стандартным набором потребностей, а с точки зрения А. Зиновьева, эта практика неминуемо превращает его в полностью атомарную субстанцию - «социального индивида». Он никогда «не живет интересами дела, а участвует в деле ради своих интересов» [14, с. 114], в силу этого его бытие определяется исключительно страхом и ужасом. И неудивительно, что в такой социальной среде терроризм, будучи формой индивидуального или даже коллективного протеста против властного насилия, получает статус постоянного официального политического оппонента биовласти, превращаясь в ее сакральную, девиантную «тень». Подобная ситуация разрушает преемственность поколений, уничтожает связь времен, конституируя антропологическую и социокультурную сингуляр- 
ность человеческой особи, от рождения и до смерти скованной в цивилизационном пространстве пароксизмом ужаса.

В то же время ужас как естественный способ бытия сообществ, составленных из подобных особей, становится не просто самостоятельным, но и ведущим общественным отношением. Это приводит к увеличению доли неконтролируемой агрессии как внутри сообщества, так и вовне. Поэтому высокая степень агрессивности и непомерно растущие с начала XX в. геополитические амбиции американского общества во многом базируются, в том числе, и на более чем столетней традиции взращивания собственного населения на голливудских фильмах ужасов.

Вообще обывательское понимание социального идеала напрямую связано с господствующими представлениями о «нормальном» и «девиантном», что порождает комплексы бессознательных проекций как у обычных людей, так и у властвующей элиты по поводу собственной непогрешимости, вседозволенности, безответственности и безнаказанности, непосредственно заимствуемых у кинематографических прототипов. Тогда как американский фильм ужасов - экранное толкование «бытия как некомфортного союза иллюзии и реальности» [15, с. 333] - выступает способом латентной, «ненасильственной», развлекающей социализации индивидов и социальных групп. Уже с самого раннего возраста он формирует у детей чрезвычайно высокий потенциал внутренней агрессии, который бессознательно аккумулируется, а затем в нужный момент канализируется властью на разрушение и подчинение иных форм мировидения, культурного и социального поведения, а также насаждения садистического доминирования и нарциссической гегемонии.

Однако у подобной идеологической доктрины существует и еще одна нелицеприятная изнанка, поскольку практическая обкатка такой модели чревата непрерывно возрастающей долей агрессивности, которую необходимо сублимировать и канализировать в безопасных и прибыльных формах потребительской коммуникации. Возникающая же при этом внутренняя «интоксикация» ужасом компенсируется иллюзией геополитической гегемонии, стремящейся постоянно экспортировать избыточный потенциал ужаса и ненависти на всю планету. Делается это посредством непрерывного участия страны в «торговых», «санкционных», «холодных», «гибридных» или откровенно «горячих» войнах (протокольно именуемых «конфликтами малой интенсивности»). Действительно, сформированной, в том числе при непосредственном участии голливудского жанра киноужаса, биовласти американского образца все-таки удалось трансформировать веками складывавшиеся представления о социальном генезисе и конкретных субъектах насилия и смерти, которая в постмодернистском социокультурном пространстве становится «центральной деятельностью по созданию стоимости» [16].

Провозглашенный же Фр. Фукуямой «конец истории», в зеркале голливудской традиции американских фильмов ужасов и вовсе предстает драматичной и кровавой хоррологией цивилизации, чье победоносное технологическое развитие было практически остановлено лавиной бессознательных комплексов, под которой в итоге и оказалась погребенной духовная жизнь общества массового потребления. В такой ситуации люди в недалеком будущем вполне могут снова превратиться в животных, «какими были до того, как кровавые битвы начали историю» [17, с. 239]. Действительно, если новейшая история европейской цивилизации началась с ницшеанского пророчества о «смерти» Бога, то постмодернизм был вынужден констатировать, помимо этого, и «фактическую» смерть героя, а также персонифицируемого ним человека, павшего жертвой разнузданных спекуляций биовласти и искусственной институциональной среды ее воспроизводства. «Идеологическая ценность подобной голливудской модели заключается 
в формировании у зрителя установки на инстинктивное освоение и отстаивание обывателем основных биотических стратегий (территории, ресурсов, моделей поведения, трофической конкуренции и т. д.) в практически полностью дебиотизированном и денатурализованном социальном и планетарном пространстве» [18, с. 93].

Однако у этой социокультурной трагедии существует и еще одна неприглядная сторона. Оказывается, что закономерным результатом властной идеологической евгеники выступает формирование и тиражирование атомизированного обывателя как сингулярной особи, поскольку именно такая особь, лишенная права на самодеятельное жизненное творчество, переведенная биовластью на искусственное «вскармливание» суррогатами и синтетически созданными биодобавками и получившая от экранного антигероя кровавый экшен-импульс, в последний момент вдруг решает диаметрально изменить властно навязанную извне биотическую программу. Показательно, что это происходит как раз в тот момент, когда последние жизненные силы и смыслы она всецело направляет на производство собственной смерти, которая зачастую оказывается первым и, к сожалению, единственным в ее жизни поступком. И действительно, прибегая к смерти как последнему способу архетипического самоосуществления, обыватель воссоздает мгновенную бессознательную иллюзию исконного символического отношения себя и мира, которого он так и не достиг в наличной институциональной «реальности» общества массового потребления. Подобное отношение априорно связывается с досознательным порывом индивида восстановить первичную архетипическую целостность отношения Себя и Мира как Матери и Дитя.

Но, к сожалению, повседневное потребление экранной смерти и страхов как ее бессознательных проекций, которые, по мнению К.Г. Юнга, «беспросветно держат человека узником в темноте бессознательного и выталкивают его в ничтожность существования» $[19$, с. 304], сублимируются в сознании и чувствах обывателя, оказывается таким же рядоположенным, рутинным, начисто лишенным интимности актом, как и любой другой момент «социального движения» индивида в обществе массового потребления. И это всякий раз подтверждается, к примеру, тем, что средства массовой информации тщательно культивируют статус как индивидуальной, так и массовой смерти в качестве повседневного, знакового, новостного события, динамически перераспределяя в процессе его капитализации виртуальное социальное пространство и переозначивая свои идеологические, а вслед за ними и иные сублимационные приоритеты.

Фактически именно непомерные геополитические амбиции современного западного мира, политико-идеологическим референтом которого являются США с их идеей «Рах Americana», формируют и представляют «идеологические медиаторы мультикультурализма» $[20$, с. 41$]$, что становится одной из причин медийной глобальной переоценки ценностей классической мифологии и культуры. В то время как подлинный мультикультурализм состоит не столько в публичной, пропагандистской демонстрации выработанного в рамках конкретной культуры «образа врага», сколько в непрерывном диалектическом обмене как самими такими образами, так и конкретными нюансами их освоения. Опять-таки, такой подход необходим не столько для выяснения баланса сил или духовного потенциала того или иного «ужасного» голливудского образа, сколько для определения меры их коллективного освоения и попытки диалектического снятия в рамках единой общечеловеческой культурной мозаики. Проведенный методологический анализ позволил, с одной стороны, зафиксировать отсутствие адекватной культурологической и социально-философской научной рефлексии в отношении традиции американских фильмов ужасов. С другой стороны, вследствие крайней ограниченности исследовательской базы в этом направлении авторы смогли лишь очертить основные 
вехи биотизации образа жизни человека в художественной традиции американских фильмов ужасов. Авторами установлено, что в качестве основной цели голливудской визуализации ужаса выступает пропаганда методов и средств оперирования природой человека, выработанных в рамках предельно рационализированной истории западной цивилизации. Популяризируемая голливудскими фильмами ужасов на весь мир концепция управления предполагает выстраивание кратологических практик на основе сублимации физиологических нужд и биотических рисков человека в стратегии и тактиках социального управления. Поэтому непрерывные спекуляции вокруг биотических характеристик бытия современного обывателя становятся доминирующими формами отправления и самопрезентации политической власти, которая в таком контексте может именоваться только биовластью. Авторы убеждены, что комплексное изучение причин и особенностей протекания взрывной эволюции культуры голливудского «ужасного» кинематографа в XX в. и особенно начале XXI в. позволит определить роль и основные сценарии трансформации медийного насилия в будущем [21] и пролить свет на генезис и тенденции развития представляемых и пропагандируемых Голливудом ключевых социокультурных и политических трендов западной цивилизации, а также и особенностей ее идеологического влияния на человечество в целом. Проанализировав выявленные тенденции, авторы приходят к выводу о том, что зарубежная и отечественная гуманитаристика стоит на пороге формирования новой междисциплинарной предметной области, которая требует совместных усилий исследователей, синергийно объединяющих все направления современной науки, занимающиеся изучением природы, человека и общества.

Исследование выполнено при финансовой поддержке РФФИ в рамках научного проекта № 18-011-00129.

\section{СПИСОК ЛИТЕРАТУРЫ}

1. Kornhaber D. American film from the silent era to the «Talkies»// Oxford Research Encyclopedia: American History. - 2019. URL: https://doi.org/10.1093/acrefore/9780199329175.013.568 (дата обращения 19.09.2019)

2. Юсев А. Ю. Кинополитика: Скрытые смыслы современных голливудских фильмов. - М.: Альпина Диджитал, 2017. - 300 с.

3. Бодрийяр Ж. Фатальные стратегии / пер. с фр. А. Качалова. - М.: РИПОЛ классик, 2017. - 288 с.

4. Freeman M. The killer who never was: complex storytelling, the Saw Saga and the shifting moral alignment of puzzle film horror // Style and form in the Hollywood slasher film / Ed. by W. Clayton. - London: Palgrave Macmillan, 2015. - P. 118-130. URL: https://doi.org/10.1057/9781137496478_9 (дата обращения 14.05.2019).

5. Некита А.Г. Нутро и поверхность: к феноменологии телесности в американском фильме ужасов // Вестник Томского государственного университета. Культурология и искусствоведение. - 2019. № 35. - C. 96-104. DOI: $10.17223 / 22220836 / 35 / 9$.

6. Ницше Ф. Воля к власти. Опыт переоценки всех ценностей / пер. с нем. Е. Герцык и др. - М.: Культурная Революция, 2005. -880 c.

7. Jancovich M. «The theme of psychological destruction»: horror stars, the crisis of identity and 1940s horror // Horror Studies. - 2015. - V. 6. - № 2. - P. 163-175. DOI: https://doi.org/10.1386/host.6.2.163_1 (дата обращения 20.05.2019).

8. Hills M. The pleasures of horror. - London; New York: Continuum, 2005. - $250 \mathrm{p}$.

9. Moreno E.T. A nightmare on Elm street: a cultural nightmare difficult to escape // BRUMAL. Revista de Investigación sobre lo Fantástico Investig ción so re lo antástico. - 2016. - V. IV. - № 2. - P. 227-246. DOI: https://doi.org/10.5565/rev/brumal.220 (дата обращения 14.05.2019).

10. Миф и художественное сознание XX века / под ред. Н. Хренова. - М.: Гос. институт искусствознания, 2011. $-686 \mathrm{c}$. 
11. Staiger J. The Slasher, the Final Girl and the Anti-Denouement // Style and form in the Hollywood slasher film / Ed. by W. Clayton. - London: Palgrave Macmillan, 2015. - P. 213-228. URL: https://doi.org/10.1057/9781137496478_15 (дата обращения 20.05.2019).

12. Hunter J. Eros in Hell. Sex, blood and madness in Japanese cinema. - UK: Creation Books, 1998. - 228 p.

13. The cult film reader / Eds. E. Mathijs, X. Mendik. - L.; N.Y.: Open University Press; McGraw Hill, 2007. $576 \mathrm{p}$.

14. Зиновьев А. Зияющие высоты. В 2 томах. Т. 1. - М.: ПИК, 1990. - 320 с.

15. Horror film reader / Ed. by A. Silver, J. Ursini. - New York: Limelight Editions, 2000. - 320 p.

16. Haskaj F. From biopower to necroeconomies: neoliberalism, biopower and death economies // Philosophy \& Social Criticism. - 2018. - V. 44. - Iss. 10. - P. 1148-1168. URL: https://doi.org/10.1177/0191453718772596 (дата обращения 14.05.2019).

17. Фукуяма Фр. Конец истории и последний человек. - М.: АСТ, 2015. - 259 с.

18. Маленко C.A. От «Final Girl» к единственной Великой Матери: голливудский хоррор и стратегии постгуманизма // Вестник Томского государственного университета. Культурология и искусствоведение. - 2019. - № 35. - С. 87-95. DOI: 10.17223/22220836/35/8.

19. Одайник В. Психология политики. Политические и социальные идеи Карла Густава Юнга / пер. с англ. - М.: Ювента, 1996. - 384 с.

20. Malenko S.A., Nekita A.G. Horror films in unconscious anthropological strategies of biopower // Anthropological Measurements of Philosophical Research. - 2018. - № 13. - P. 41-51. DOI: 10.15802/ampr.v0i13.122984.

21. Abel M. The violence of sensation: Miller's crossing, affect, and masocriticism // Violent Affect: Literature, Cinema, and Critique after Representation. - Lincoln; London: University of Nebraska Press, 2007. - P. 1-28. DOI: $10.2307 /$ j.ctt1djmcw8.5.

Поступила 19.10.2019 2. 


\title{
BIOLOGIZATION OF LIFESTYLE OF THE INHABITANT IN THE IDEOLOGICAL TRADITION OF AMERICAN HORROR FILM
}

\author{
Sergey A. Malenko, \\ olenia@mail.ru \\ Andrey G. Nekita, \\ beresten@mail.ru \\ Yaroslav-the-Wise Novgorod State University, \\ 41, B. St. Petersburgskaya street, Veliky Novgorod, 173003, Russia.
}

Sergey A. Malenko, Dr. Sc., professor, head of the Department of philosophy, cultural studies and sociology, Yaroslav-the-Wise Novgorod State University.

Andrey G. Nekita, Dr. Sc., professor, Yaroslav-the-Wise Novgorod State University.

Relevance. Reinterpretation of classical political dominants actualizes the meanings of interaction between the state, society and individual. The rejection of direct physical coercion encourages the search for ideological mechanisms of social control. Hollywood is becoming a media mouthpiece for the biotic transformation of politics, and horror film is becoming the most effective model for visualizing these technologies. The aim. The article analyzes the strategies of biotization of everyday life in the space of modern mass culture through the ideological expansion of American horror films. Research. Domestic and foreign authors state the transformation of classical ideology into latent forms of control at the level of official and everyday practices. Methods. The article uses a complex of comparative, semiotic and psychoanalytic methods analyzing the artistic experience of cinema and its mythology. Results. Hollywood horror films are a proven means of sublimation, deformation and consumer substitution of the mental core of any competing socio-cultural traditions. American visual horror-culture effectively displaces the potential of aggression within the country, turning into a lucrative propaganda technology for formation and promotion of pathomif. It reproduces mainly physiological motives of communication of the individual with the world, promotes the ideological dominant of the biologically strong individual as the foundation of socio-cultural communication of the posthuman type. American horror film nullifies the existential experience of mankind; it is at the forefront of the revision of the traditions of not only European but also world culture. Findings. The Hollywood model of bio-power destroys cultural traditions and historical experience, constructs anthropological and socio-cultural singularity of the human individual, and periodically accumulating «intoxication» with Hollywood horror is compensated by the illusion of American geopolitical hegemony.

Key words: American horror films, ideology of fear, bio-power, sublimation, displacement, philistine, mass culture.

The reported study was funded by RFBR according to the research project no. 18-011-00129.

\section{REFERENCES}

1. Kornhaber D. American film from the silent era to the «Talkies». Oxford Research Encyclopedia: American History, 2019. Available at: https://doi.org/10.1093/acrefore/9780199329175.013.568. (accessed 19 September 2019). 
2. Yusev A.Yu. Kinopolitika: Skrytye smysly sovremennykh gollivudskikh filmov [Film politics: the hidden meanings of modern Hollywood films]. Moscow, Alpina Didzhital Publ., 2017. 300 p.

3. Bodriyyar Zh. Fatalnye strategii [Fatal strategies]. Translated from French by A. Kachalov. Moscow, RIPOL klassik Publ., 2017. 288 p.

4. Freeman M. The killer who never was: complex storytelling, the Saw Saga and the shifting moral alignment of puzzle film horror. Style and form in the Hollywood slasher film. Ed. by W. Clayton. London, Palgrave Macmillan, 2015. pp. 118-130. Available at: https://doi.org/10.1057/9781137496478_9 (accessed 14 May 2019).

5. Nekita A.G. Insides \& surface: to the phenomenology of physicality in the American horror film. Vestnik Tomskogo gosudarstvennogo universiteta. Kulturologiya $i$ iskusstvovedenie, 2019, no. 35, pp. 96-104. In Rus. DOI: 10.17223/22220836/35/9.

6. Nitsshe F. Volya $k$ vlasti. Opyt pereotsenki vsekh tsennostey [Will to power. Experience of revaluation of all values]. Moscow, Kulturnaya Revolyutsiya Publ., 2005. 880 p.

7. Jancovich M. «The theme of psychological destruction»: Horror stars, the crisis of identity and 1940s horror. Horror Studies, 2015, vol. 6, no. 2, pp. 163-175. DOI: https://doi.org/10.1386/host.6.2.163_1.

8. Hills M. The Pleasures of Horror. London, New York, Continuum, 2005. 250 p.

9. Moreno E.T. A nightmare on Elm Street: a cultural nightmare difficult to escape. BRUMAL. Revista de Investigación sobre lo Fantástico Investig ción so re lo antástico, 2016, vol. IV, no. 2, pp. 227-246. DOI: https://doi.org/10.5565/rev/brumal.220.

10. Mif $i$ khudozhestvennoe soznanie XX veka [Myth and artistic consciousness of the XX century]. Ed. by N. Khrenov. Moscow, Gos. institut iskusstvoznaniya Publ., 2011. 686 p.

11. Staiger J. The Slasher, the Final Girl and the Anti-Denouement. Style and form in the Hollywood slasher film. Ed. by W. Clayton. London, Palgrave Macmillan Publ., 2015. pp. 213-228. Available at: https://doi.org/10.1057/9781137496478_15 (accessed 20 May 2019).

12. Hunter J. Eros in Hell. Sex, blood and madness in Japanese cinema. UK, Creation Books, 1999. 232 p.

13. The cult film reader. Eds. E. Mathijs, X. Mendik. London, New York, Open University Press Publ., McGraw Hill Publ., 2007. 576 p.

14. Zinovev A. Ziyayushchie vysoty [Gaping heights]. Moscow, PIK Publ., 1990. Vol. 1, 320 p.

15. Horror film reader. Eds. A. Silver, J. Ursini. New York, Limelight Editions Publ., 2000. 320 p.

16. Haskaj F. From biopower to necroeconomies: neoliberalism, biopower and death economies. Philosophy \& Social Criticism, 2018, vol. 44, Iss. 10, pp. 1148-1168. Available at: https://doi.org/10.1177/0191453718772596 (accessed 14 May 2019).

17. Fukuyama Fr. Konets istorii i posledniy chelovek [The end of history and the last man]. Moscow, AST Publ., 2015. 259 p.

18. Malenko S.A. From the «Final Girl» to a single Great Mother: Hollywood horror and the strategy of posthumanism. Vestnik Tomskogo gosudarstvennogo universiteta. Kulturologiya i iskusstvovedeniye, 2019, no 35, pp. 87-95. In Rus. DOI: 10.17223/22220836/35/8.

19. Odaynik V. Psikhologiya politiki. Politicheskie i sotsialnye idei Karla Gustava Yunga [Psychology of politics. Political and social ideas of Carl Gustav Jung]. Moscow, Juventas Publ., 1996. 384 p.

20. Malenko S.A., Nekita A.G. Horror films in unconscious anthropological strategies of biopower. Anthropological Measurements of Philosophical Research, 2018, no. 13, pp. 41-51. DOI: 10.15802/ampr.v0i13.122984.

21. Abel M. The violence of sensation: Miller's crossing, affect, and masocriticism. Violent Affect: Literature, Cinema, and Critique after Representation. Lincoln, London, University of Nebraska Press Publ., 2007. pp. 1-28. DOI: $10.2307 /$ j.ctt1djmcw8.5.

Received: 19 October 2019. 